\title{
BIONOMICS OF TSETSE AND OTHER PARASITOLOGICAL NOTES IN THE GOLD COAST,
}

\author{
By Dr. JAmes J. Stmpson, \\ Imperial Bureau of Entomology.
}

CONTENTS.

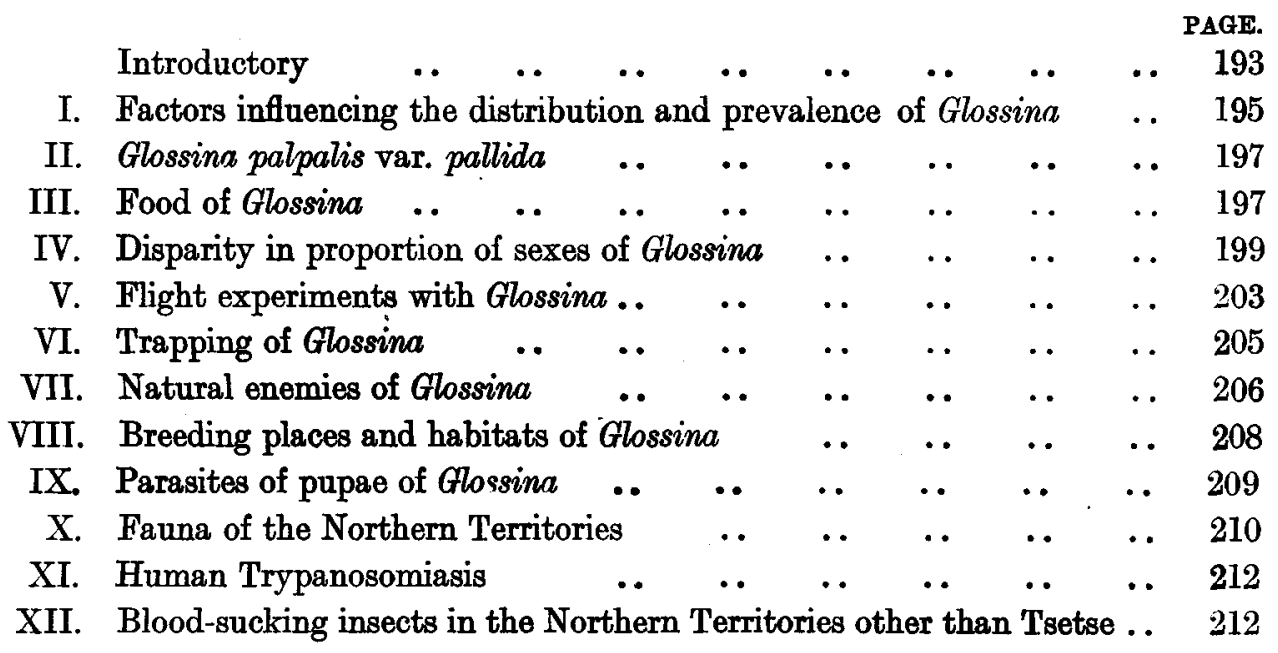

The following report is based on a tour which extended from September 1915 to February 1917, but included in it are also some observations made during a few months residence in 1914.

The area comprised lies partly in the Northern Territories of the Gold Coast, and partly in Togoland (see Map, Bull. Ent. Res., V, p. 32). It extends trom $8^{\circ} \mathrm{N}$. to $9^{\circ} 45^{\prime} \mathrm{N}$. and from $.0^{\circ} 15^{\prime} \mathrm{E}$. to $2^{\circ} 30^{\prime} \mathrm{W}$. My headquarters were at Yapi on the River Volta about 28 miles south-west of Tamale, the capital of the Northern Territories. I have already described in a previous report* the nature of the country and the type of vegetation, so need not repeat them here. I examined the whole of the Volta from Yapi to Yeji by canoe, and then followed a sinuous route on my return journey, keeping as close to the River as possible. The country between Yapi and Daboya, a large town with an important ferry on the Volta, was traversed on several occasions. From Daboya I went to Bole and made my temporary headquarters at Larabanga, the centre of the game and Glossina submorsitans area. Here I spent several weeks under canvas in three separate localities in the bush. On my homeward

* Bulletin of Entomological Research, v, pp. 1-36.

(C419) Wt.P7/121. 1,000. 2.18. B.\&F.Ltd. G.11/1. 
journey I visited Yendi, formerly an important German post in Togoland, thence going to Salaga and Kete-Krachi, where I crossed the Volta and proceeded to join the main north road at Atabubu (Tabobo).

This report must be taken in conjunction with my previous report already referred to. It may be advisable to point out here that many of my notes were lost on my homeward voyage, so that certain sections of this account of my work are not so complete as they might otherwise have been. For all practical purposes, however, the actual conclusions arrived at are in accordance with the observations made.

Appended is a table showing the weekly rainfall from 1st June, 1915, to 31st December, 1916. This is the meteorological condition which most greatly affects the seasonal prevalence of tsetse, and also to a great extent puts a limit to bush work. This table should be consulted when reading inter alia the section on the "Disparity in the proportion of sexes of Glossina."

\begin{tabular}{|c|c|c|c|c|c|c|c|}
\hline \multicolumn{3}{|c|}{ Month. } & \multirow{2}{*}{$\begin{array}{c}\text { lst week. } \\
1.81\end{array}$} & \multirow{2}{*}{$\frac{\text { 2nd week. }}{\text { nil }}$} & \multirow{2}{*}{$\frac{\text { 3rd week. }}{1.83}$} & \multirow{2}{*}{$\begin{array}{c}\text { 4th week. } \\
1 \cdot 63\end{array}$} & \multirow{2}{*}{\begin{tabular}{|c|c|}
$\begin{array}{c}\text { Total } \\
\text { for month. }\end{array}$ \\
$5 \cdot 27$
\end{tabular}} \\
\hline June & $\cdots$ & $\cdots$ & & & & & \\
\hline July & . & $\ldots$ & $1 \cdot 25$ & $2 \cdot 03$ & $2 \cdot 74$ & nil & $6 \cdot 02$ \\
\hline August & . & $\therefore$ & $n i l$ & $0 \cdot 73$ & $2 \cdot 21$ & 1.91 & $4 \cdot 85$ \\
\hline Septemb & & . & $2 \cdot 92$ & $2 \cdot 68$ & 0.05 & $2 \cdot 69$ & $8 \cdot 34$ \\
\hline October & . & . & $1 \cdot 43$ & 0.34 & 0.54 & $0 \cdot 35$ & $2 \cdot 66$ \\
\hline Noremb & & $\cdots$ & $n i l$ & nil & nil & nil & $n i l$ \\
\hline Decembe & & . & nil & nil & nil & nil & nil \\
\hline January & & $\cdots$ & nil & nil & nil & $n i l$ & nil \\
\hline Februar & & . & nil & $n i l$ & nil & nil & nil \\
\hline March & . & $\cdots$ & $0 \cdot 11$ & nil & $0 \cdot 83$ & $0 \cdot 60$ & 1.54 \\
\hline April & .. & $\cdots$ & $1 \cdot 20$ & 0.85 & $0 \cdot 15$ & $2 \cdot 57$ & $4 \cdot 77$ \\
\hline May & . & $\cdots$ & $1 \cdot 83$ & nil & $3 \cdot 25$ & 0.92 & $6 \cdot 00$ \\
\hline June & . & $\cdots$ & $1 \cdot 61$ & $2 \cdot 49$ & $0 \cdot 88$ & $0 \cdot 35$ & $5 \cdot 33$ \\
\hline July & . & $\cdots$ & $1 \cdot 70$ & $2 \cdot 30$ & $0 \cdot 47$ & 1.97 & $5 \cdot 44$ \\
\hline August & . & $\cdots$ & $1 \cdot 96$ & 0.97 & $1 \cdot 78$ & $8 \cdot 57$ & $13 \cdot 28$ \\
\hline Septemb & ber & $\therefore$ & $1 \cdot 73$ & $0 \cdot 74$ & $0 \cdot 87$ & $1 \cdot 29$ & $4 \cdot 63$ \\
\hline October & $\cdots$ & $\cdots$ & $1 \cdot 48$ & $0 \cdot 99$ & $0 \cdot 34$ & nil & $2 \cdot 71$ \\
\hline Novemb & & . & nil & nil & $1 \cdot 17$ & $0 \cdot 70$ & $1 \cdot 87$ \\
\hline Decemb & & .. & nil & nil & nil & nil & nil \\
\hline
\end{tabular}




\section{Factors Influencing the Distribution and Provalence of Tsetse.}

Dr. Shircore* has drawn attention to what he calls "primary centres" in which he says that Glossina morsitans segregate at the period when the conditions of life are unfavourable elsewhere, and from which they disperse when water becomes abundant and the country is covered with grass and the trees with foliage. Several writers on this question in West Africa also refer to " fly-belts." This term has been so loosely used that it is sometimes difficult to establish what is actually meant. If by a "flybelt" is meant that at certain parts on a road tsetse are more abundant than elsewhere, then such a state of affairs actually exists, but if by the term it is meant to indicate that at certain parts these flies exist in numbers and are not to be found elsewhere in the surrounding country, then the term is misleading and not in accordance with the facts. In all my experience in West Africa I am not conscious of any definite locality, either in the wet or dry season, containing tsetse actually cut off from the surrounding country. To a casual observer this might appear to be so, but if the intermediate country be thoroughly examined, it will be found that tsetse exist linking up these so-called belts, though undoubtedly in smaller numbers.

At the end of the dry season (December, January and February in West Africa), when the forest fires are raging, tsetse (along with game) are undoubtedly driven before them and take refuge in the denser bush unattacked by such fires, but the pupae are seldom damaged and soon repopulate the area burnt, in addition to the adults which return after a very-short time. Thus, if an area over which an extensive bush fire has been raging be examined immediately after the fire, no tsetse will be encountered, but if the same area be examined a month later, tsetse will again be found. This is a condition of a purely artificial character, and has no definite relation to the natural segregation of the flies.

In the Northern Territories of the Gold Coast at any rate, it is no doubt the case that there is hardly a square mile where tsetse cannot be captured at some period of the year. This is extremely important in the case of horse transport. In these Territories certain areas are "proclaimed" for horses, but this precaution only leads to a false security. There is no road between any two stations in the Northern Territories free from tsetse, and as it is not the actual number of the flies, but the proportion infected that counts, such a regulation is worse than useless.

Type of Vegetation.-I have already in my reports on the different colonies in West Africa given the types of vegetation associated with the various species of tsetse found there, so need not reiterate these observations here. Briefly summarised, these might be given as follows:-G. palpalis is found along the banks of rivers where vegetation is dense, in "kurimis" (dense bush with abundant shade), and along the banks of the smaller tributaries. G. tachinoides is an up-country form allied to G. palpalis, and is found in similar localities on the higher reaches of the rivers. G. submorsitans is seldom found near rivers and is more abundant in the savannah forest and open savannah country; I have found the species at least three miles from the nearest water. In very open country where small water-holes exist, $G$. submorsitans is more frequent, but this may be, and probably is, because game comes to water there. G. submorsitans will, however, follow a herd of game a long distance, and undoubtedly migrates in this manner.

* Bull. Ent. Res., v, p. 87 
Relation to Game.-Lloyd has drawn attention to the fact that where game is plentiful 13 per cent. of female $G$. morsitans were caught, whereas where game was not plentiful 41.5 per cent. of females were taken. This relationship is confirmed by my observations in West Africa. At Larabanga game is extremely abundant, and during 22 days' collecting in July and August the percentage of females was 9.2. At Murugu, on the other hand, where native hunters are numerous and game consequently scarce, the percentage in June was 54, while in August it was 15. Lloyd also remarks that when game is plentiful the number of pupae taken daily was 31, whereas where game is not plentiful the number was only 7. This is also borne out in West Africa. These two facts, contradictory as they may seem, are yet easily accounted for, and are what one would expect. Where game is abundant the females manage to feed easily, and when fully gorged retire to the seclusion of some shady place, consequently the number of females seen and caught is diminished. Following on this is the fact that if the females feed easily they propagate more rapidly, consequently the number of pupae is increased.

All over the Northern Territories the close association between $G$. submorsitans and game is very marked. Wherever game is abundant, there tsetse will be in like proportion. I have elsewhere remarked on the fact that my attention has frequently been drawn to the presence of game by observing an increase in the number of tsetses. The table showing the proportion of the sexes in $G$. submorsitans will bear out this association, e.g., at Larabanga, where game is plentiful, the average daily number of G. sutmorsitans taken was over 100 , whereas at Murugu (between Larabanga and Daboya) where game is kept under by native hunters the daily average was about 50 . The nature of the fauna and its association with tsetse has often been commented upon, but in West Africa I have never seen any marked disparity in the number of G. submorsitans associated with buffalo or warthog, although I have followed and shot practically every species of game in the country. I have elsewhere remarked on the close association between $G$. submorsitans and.the dog-faced baboon (Papio sphinx), and this fact was again brought to my notice during my past tour. At one camp where my collectors brought back very few tsetse, I naturally enquired the reason, and they explained that there were no monkeys. Now as my carriers that day caught a small monkey I pointed this fact out to them, but they explained that it was not the small monkeys they meant, but the dog-faced baboons. They also said that where the baboons were abundant tsetse were also abundant. This fact is difficult of explanation, as it is highly improbable that tsetse feed on these animals, yet if such an association be established, the question of exterminating tsetse by the destruction of game becomes exceedingly more difficult.

Meteorological Conditions.--I have elsewhere discussed this question in extenso, but would point out that humidity is the prevailing factor influencing the numbers of tsetse. At the beginning of the dry season these insects increase greatly in numbers. Whereas actual sunshine only affects the daily period of activity, a hot sun most strongly affects $G$. palpalis, which seldom follows one in direct sunshine. G. tachinoides is next affected, whereas $G$. submorsitans will follow and attack in the open in the hottest sun, but seldom at night. Roubaud states that $G$. morsitans when exposed to a temperature of $40^{\circ} \mathrm{C}$. (104 $4^{\circ} \mathrm{F}$ ) died within an hour. This I did not find to be the case in the Northern Territories. I have frequently caught them in the open at 
a temperature of $109^{\circ}$ and $112^{\circ}$ F. For this reason, when cattle, horses, and other animals have to be transferred from one place to another, this should be done if possible during the night.

\section{Glossina palpalis var. pallida, var. nov.}

One of the greatest difficulties I experienced in identifying tsetse was in regard to a small variety of $G$. palpalis. This variety was first found by me in the upper reaches of the River Gambia. At that time (1911) I reserved an opinion as to its identity. Subsequently, Dr. Macfie found them in large numbers in the Ilorin province of Northern Nigeria. In his report on that province (Bull. Ent. Research, iv, p. 13) he makes some observations on the characteristics of the variety and gives an excellent illustration of it (Plate vii). At Yapi I found very few typical G. palpalis but large numbers of this variety. It is almost identical in size and markings with $G$. tachinoides, but an examination of the genital armature of a very large number leaves one in no doubt as to its identity with $G$. palpalis. When females are gorged with blood, however, or have become discoloured, it is almost impossible to distinguish them.* The variety is so distinct in size and markings from $G$. palpalis, which prior to Newstead's study of the genital armature were the only specific characters, that I think it advisable to give some distinctive name, such as var. pallida to this race. It is especially worthy of note that no intermediate forms exist between this variety and typical $G$. palpalis.

\section{Food of Glossina.}

The question as to whether tsetse are entirely dependent on blood for their food supply, and if so, what blood is most acceptable, calls for some comment.

Several writers have devoted much space to this question, but the problem is far from being actually solved. Bruce and others in discussing the matter cite the following cases in regard to G. palpalis:-(1) in 60 flies in which blood was found, 20 contained mammalian, 9 non-mammalian, and 31 unrecognisable blood; (2) in 108 other flies, 7 contained mammalian, 35 non-mammalian, and 66 unrecognisable blood.

With regard to the latter instance they note that reptilian was twice as frequentas avian.

Yorke and Blacklock give the following data from Sierra Leone :-

\begin{tabular}{ccc} 
Flies. & Mammalian. & Nucleated. \\
113 & 8 & 0 \\
87 & 6 & 2 \\
$\overline{200}$ & $\overline{14}$ & - \\
\hline
\end{tabular}

These figures show great discrepancies; e.g. in Bruce's first record the proportion of mammalian to non-mammalian is over 2 to 1 ; in his second the proportion is as 1 to 5 ; while in Yorke and Blacklock's observations the proportion is 7 to 1 .

* [In G. tachinoides the third joint of the antenna is noticeably shorter and its anterior edge is less curved.-ED.] 
With regard to $G$. morsitans the following data are available. Bruce in his Report of the Sleeping Sickness Commission of the Royal Society states that out of 500 flies examined 288 or $57 \cdot 6$ per cent. contained mammalian blood, while only three contained nucleated corpuscles, and two contained a mixture of both. Of 30 female flies examined he states that 13 , or 43.3 per cent. contained mammalian blood. In another experiment he notes that 99 per cent. contained mammalian blood and only 1 per cent. avian.

Lloyd states that out of 67 flies examined 24 per cent. contained mammalian blood, and 7.4 non-mammalian.*

Eminson in 1914 found that out of 500 flies examined there was blood in 43 ; in 41 there was mammalian blood, and two contained non-mammalian.

This would tend to show that $G$. morsitans is much more dependent on mammalian blood than is $G$. palpalis. I had very little opportunity of studying the latter species in large numbers, but several thousands of $G$. tachinoides were examined microscopically for stomach contents. In none of these could I detect anything of a vegetable character. At Yapi 1,289 G. tachinoides were captured containing blood. The percentage of mammalian and non-mammalian blood in the different batches examined varied considerably, but taking the observations as a whole the result was as follows : Mammalian $67 \cdot 3$ per cent., non-mammalian $32 \cdot 7$ per cent.

Other observations at different places gave the following figures :-

$\begin{array}{ccc}\text { Flies. } & \text { Mammalian blood. } & \text { Non-mammalian blood. } \\ 375 & 59 \% & 41 \% \\ 287 & 68 \cdot 5 \% & 31 \cdot 5 \% \\ 329 & 74 \cdot 3 \% & 26 \cdot 7 \%\end{array}$

It must be remembered that out of those taken with mammalian blood a certain number must be deducted, as undoubtedly many of them had bitten the collectors. This fairly exhaustive experiment goes to show that non-mammalian blood forms a distinct food supply for $G$. tachinoides, and the point is raised : What is the source of this food supply? In my animal house at Yapi I kept various types of reptiles, including the puff adder (Bitis arietans), black cobra (Naia nigricollis), the yellowspotted monitor (Varanus niloticus), and the common crocodile (Crocodilus niloticus), and have repeatedly seen $G$. tachinoides gorge itself on each and all of these species. This is especially the case after these animals have had a heavy meal and are very somnolent. On one occasion at Prang on the River Pru I came across a large sleeping puff adder on which one $G$. palpalis and two $G$. tachinoides were feeding.

Observations on birds were very different. Very few $G$. tachinoides managed to get a full meal from any of the species kept. They never fed on fowls unless these were tied down. This would distinctly point to reptilian rather than avian fauna as the source of food in the case of those found with nucleated corpuscles; and reptiles are extremely common all along the river banks where $G$. tachinoides abound.

The source of the mammalian blood is not so easy of solution. Various species of small and large game come to the river in the mornings and evenings to drink, and of

* [In Northern Rhodesia, Kinghorn, Yorke and Lloyd record (Ann. Trop. Med. Paras., vii, 1913, p. 282) that out of 82 flies containing recognisable blood, 12 (or $14 \cdot 6$ per cent.) contained nucleated red cells.-ED.] 
course numbers of them must be bitten; but although the river banks everywhere abound with baboons and monkeys, I think it highly improbable that these form a source of food supply. I kept two Cercopithecus patas for nearly two years, and never once did I see a tsetse manage to feed off them. Even when apparently asleep, the monkeys at once disturbed the tsetse on alighting, and in the great majority of cases succeeded in catching and devouring them. There is, however, one small mammal which is extremely abundant on the banks of the Volta River, and that is a large yellowish brown bat. These animals sleep during the day in a suspended position in the dense overhanging trees in localities similar to those where $G$. tachinoides abound, and I am inclined to think that, apart from the human supply, these animals are the chief source of the mammalian blood supply.

I carried out a large series of experiments to find out whether tsetse ever imbibe water, but in none of these could I definitely say that such was the case. I used several tubes containing citrated blood, pure water and various coloured liquids, each covered with a membrane of rat's skin. Although at different times tsetse pierced each of these membranes, in no case could I say that any liquid was imbibed except the fresh blood. Never have I seen a tsetse drink an exposed liquid. G. tachinoides, just like $G$. morsitans, seems to prefer piercing before sucking. Several experiments with fruit, e.g., ripe pawpaw, mangoes, and ripe marrows also proved negative. Although the tsetse were seen to pierce the skin, never did I actually see any liquid being absorbed.

The percentage of mammalian blood to non-mammalian differs greatly in the case of $G$. submorsitans.

Out of 987 tsetse examined with discernible blood in the stomach, only 23 contained non-mammalian blood, i.e., only $2 \cdot 3$ per cent. The reason for this is not far to seek. In the open country away from water where $G$. submorsitans abounds, there is practically no reptilian fauna, so that it is lack of opportunity rather than preference which decides the matter. To test this I put large numbers of $G$. submorsitans into cages with different reptiles and nearly all fed voraciously and had distended abdomens, especially in the early morning.

A point of interest which obtruded itself on me on several occasions was that when an animal had been shot, tsetse and Tabanids often alighted on the carcase. Although the Tabanids frequently drank from the open wound, tsetse were never seen to do this, but always pierced the skin, and so imbibed. This leads one to suppose that $G$. submorsitans never drinks exposed liquids.

\section{Disparity in the Proportion of Sexes in Glossina.}

The question of the disparity in the proportion of sexes in Glossina has attracted the attention of many observers in various parts of Africa.

Dr. R. E. McConnell (Bull. Ent. Res., iii, p. 58) was impressed by the apparent marked numerical superiority of males along the large rivers, and of females on the smaller streams. He quotes as an example that of 40 specimens of $G$. palpalis (fuscipes) taken in October on the Nile, 35 were males and 5 females, while of 77 taken in July 67 were males and 10 females. He goes on to point out that of 56 flies captured in September near the mouth of small tributaries of the Nile 24 were males 
and 32 females, and expressed his opinion that if this last batch of flies had been taken some 20 miles upstream the females would have outnumbered the males to a much greater extent.

Dr. J. B. Davey (Bull. Ent. Res., i, p. 145) states that of 117 G. brevipalpis captured during the evenings at Kaporo in Nyasaland, all were males, whereas of seven caught in the same place about mid-day four were males and three females.

Bequaert gives a further reason for the disparity in proportion of sexes, and in discussing $G$. palpalis says that in inhabited regions the sexes are in about equal numbers, whereas in uninhabited regions there is a distinct preponderance of males. He says this may be due to the fact that food supplies are more scarce in the latter districts and therefore the more active male is more in evidence.

Kinghorn and Montgomery report the following catches of $G$. palpalis on the island of Matondwi, near the southern shore of Tanganyika :-

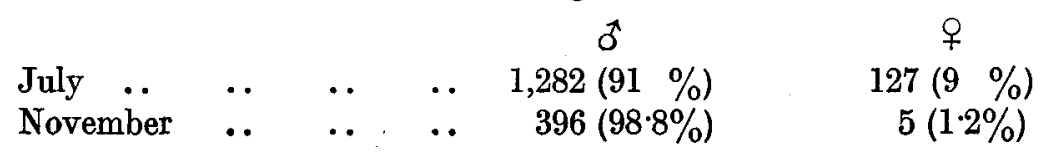

Newstead (Report S. S. Comm. of Royal Society, No. 15) gives the following table with regard to $G$. morsitans.

\begin{tabular}{|c|c|c|c|c|c|c|}
\hline Month. & & $\begin{array}{l}\text { No. of Days } \\
\text { Flies examined. }\end{array}$ & $\begin{array}{l}\text { Total } \\
\text { Flies. }\end{array}$ & & & $\begin{array}{l}\text { Meteorological } \\
\text { Condition. }\end{array}$ \\
\hline August 7-29 & .. & 7 & 87 & 80.5 & $19 \cdot 5$ & Very dry. \\
\hline Sept. $\quad 1-30$ & . & 22 & 346 & $81 \cdot 6$ & $12 \cdot 4$ & \\
\hline Oct. $1-16$ & . & 11 & 206 & $90 \cdot 8$ & $9 \cdot 2$ & , \\
\hline Oct. 17-31 & .. & 11 & 165 & $68 \cdot 5$ & $31 \cdot 5$ & Very heavy rains. \\
\hline
\end{tabular}

Thus we have such hypothetical reasons to explain the disparity in the proportion of sexes, as (1) the size of the river on which the tsetse were caught, (2) the time of capture, (3) the number of inhabitants in a given area, and (4) the season of the year and meteorological conditions.*

To all of these I paid special attention during my recent tour. As, however, at certain times I was in an area where $G$. tachinoides predominated and at others where $G$. submorsitans predominated, I was unable to make a consecutive study of either.

The number of days spent in collecting as a basis for percentages has a very direct bearing on the validity of such deductions ; e.g., at Yapi from 1st to 12th June, 1916, 856 males and 767 females were caught. This works out at 52.8 per cent. of males and 47.2 per cent. of females. Now let us break up this period into three shorter

* [A much more probable explanation of this disparity has been given independently by Ll. Lloyd (Bull. Ent. Res., iii, p. 235) and W. A. Lamborn (Bull. Ent. Res., vi, p. 250; and vii, p. 39).-ED.] 
periods, say 1st to 4th June, 5 th to 10 th June, and 11th to 12th June. The numbers and percentages are as follows :-

$\begin{array}{lccc}\text { 1st-4th } & \text { June } & \ldots & 206(52 \cdot 1 \%) \\ 5 \text { th-10th } & \# & \ldots & 523(60 \cdot 4 \%) \\ \text { 11th-12th } & \text { " } & \ldots & 127(35 \cdot 1 \%)\end{array}$

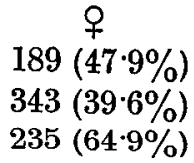

Now the enormous disparity in the percentages in these three periods compared with that in the total period is very marked. Consequently, were one to take any one of these short periods as a basis for deduction, the conclusion would not be in any way in accordance with facts over a longer period.

The longer the period over which observations are made, provided the meteorological conditions are fairly constant, the greater will be the validity of the conclusions. Again, the larger the number caught," the greater will be the chance of coming to a definite decision. This is almost a truism, but it has been so much overlooked that it is worthy of emphasis here.

Now let us take some definite cases, e.g., at Yapi. The following are the results of prolonged investigation :-

\begin{tabular}{|c|c|c|c|c|c|c|}
\hline & & & $\hat{0}$ & 웅 & $\begin{array}{l}\text { Total No. } \\
\text { examined. }\end{array}$ & Rainfall. \\
\hline June 1914 & . & $\ldots$ & $70 \%$ & $30 \%$ & & \\
\hline July 1914 & . & .. & $57 \%$ & $43 \%$ & & \\
\hline Sept. 1915 & .. & $\ldots$ & $56.5 \%$ & $43 \cdot 5 \%$ & 2,876 & $8 \cdot 34$ \\
\hline Oet. 1915 & . & . & $46.5 \%$ & $53.5 \%$ & 3,526 & $2 \cdot 66$ \\
\hline Nov. 1915 & . & . & $47 \cdot 5 \%$ & $52 \cdot 5 \%$ & 3,497 & nil \\
\hline Dec. 1915 & . & $\cdots$ & $50 \%$ & $50 \%$ & 2,985 & nil \\
\hline 1-12 June 1916 & . & $\cdots$ & $47 \cdot 2 \%$ & $52 \cdot 8 \%$ & 1,733 & $2 \cdot 71$ \\
\hline 3-12 Sept. 1916 & . & $\cdots$ & $64 \%$ & $36 \%$ & 183 & $; 4 \cdot 63$ \\
\hline
\end{tabular}

It will be seen from the above that the greatest disparity in the proportion of sexes occurs during the period of greatest rainfall.

Now at Daboya the following are the results :-

\begin{tabular}{lll|c|c|c|c}
\hline & & & $\sigma$ & $q$ & $\begin{array}{c}\text { Total No. } \\
\text { examined. }\end{array}$ & Rainfall. \\
\hline $29,30$. iii.16 & $\ldots$ & $\ldots$ & $60 \%$ & $40 \%$ & 142 & $1 \cdot 54$ \\
$21,27$. vi.16 & $\ldots$ & $\ldots$ & $58 \%$ & $42 \%$ & 907 & $5 \cdot 33$ \\
$23,24$. vii.16 & $\ldots$ & $\ldots$ & $50 \%$ & $50 \%$ & 215 & $5 \cdot 44$ \\
\hline
\end{tabular}

The results here obtained are almost in direct contradiction with those previously shown for Yapi. 
Again, take the case of Gnani and Danio in Togoland. These places are practically identical in every way, yet at the former three days' collecting resulted in the following-127 males and 194 females; while at the latter the position was reversed, and 126 males were caught to 114 females.

On the River Lora between Larabanga and Daboya, in April 1916, the proportion of males and females was as 51.5 to 48.5 ; rainfall $4 \cdot 77$. This river satisfies two of the conditions insisted on by McConnell and Bequaert. It is a small tributary of the Volta, and it is several hours from the nearest village, consequently uninhabited. Yet in the case of $G$. tachinoides, if we may judge from the results here found, neither of these factors has any bearing on the proportion of the sexes. But it is only right to point out that these authors were dealing with $G$. palpalis.

At Zantana (N. of Daboya) in the same month, April, the relation was 57 per cent. males and 43 per cent. females. This village is also on a small tributary of the Volta, but the difference in percentages of the sexes is not appreciable.

At Gwa, a small village S.E. from Daboya far removed from the River Volta, in March 1916 the proportion was as 62 to 38 per cent.

At Kito, a similar locality, a little further south in the same month the proportion was as 65 to 35 per cent.

The one outstanding feature which these figures exhibit is that the percentage of males decreases as the rains gain in intensity and the humidity increases. (Compare this with G. submorsitans).

Now let us consider the case of $G$. submorsitans, and see how far the proportion of sexes is in accordance with the figures found for $G$. tachinoides. The following table has been prepared for various localities in the Northern Territories at different seasons.

It will be seen that Larabanga was visited at four different periods in July and August, but that the percentages are practically the same. In the case of Murugu and Kapoto (some miles S.W. from Daboya) the difference between June and August requires some explanation.

\begin{tabular}{|c|c|c|c|c|c|c|c|c|}
\hline & & & & & & & Perc & age. \\
\hline Larabanga & .. & . & . & 1-7. vii.16 & 721 & $100)$ & & \\
\hline ". & .. & . & $\ldots$ & 14-18. vii.16 & 546 & 47 & & \\
\hline " & . & . & . & $25-28$. vii. 16 & 202 & 9 & $90 \cdot 8$ & $9 \cdot 2$ \\
\hline , & .. & $\ldots$ & $\ldots$ & 15-21. viii. 16 & 816 & 78 & & \\
\hline Kabampwi & .. & $\ldots$ & . & 29. vii. 16 & 52 & 4 & $90 \cdot 7$ & $9 \cdot 3$ \\
\hline Guripe & .. & . & . & 30. vii-3. viii. 16 & 300 & 33 ) & & \\
\hline , & . & . & . & 11-14.viii.16 & 69 & $6\}$ & 91 & $\mathbf{y}$ \\
\hline Murugu & $\cdots$ & . & $\ldots$ & 31. vi.16 & 25 & 29 & 46 & 54 \\
\hline . & $\ldots$ & . & $\ldots$ & 21.viii.16 & 46 & 8 & 85 & 15 \\
\hline Yarizori & $\ldots$ & . & $\ldots$ & 22. viii. 16 & 58 & 4 & $91 \cdot 5$ & $8 \cdot 5$ \\
\hline Kapoto & . & . & .. & 28. vi.16 & 80 & 52 & 60 & 40 \\
\hline ", & . & . & $\ldots$ & 23.viii.16 & 109 & 5 & 93 & 7 \\
\hline Kofaba & $\ldots$ & $\ldots$ & . & 4-9. ii.16 & 261 & 76 & $44 \cdot 5$ & $55 \cdot 5$ \\
\hline Larabanga & Bush & Camp I. & & 14-20. vi. 16 & 660 & 38 & $94 \cdot 5$ & $5 \cdot 5$ \\
\hline Larabanga & Bush & Camp I] & & $23,24 . \quad$ v. 16 & 268 & 14 & 95 & 5 \\
\hline Larabanga & Bush & Camp I] & II. & 8-13. vii.16 & 336 & 36 & 91 & 9 \\
\hline
\end{tabular}


From the foregoing table it is quite evident that there is a much greater disparity in the proportion of the sexes of $G$. submorsitans than in the case of $G$. tachinoides. The general average ranges from 90-95 per cent. of males, but there are certain discrepancies; e.g., at Murugu in June the percentage of males was only 46, while in August it was 85. This is probably accounted for by the greater rainfall between June and August than in the preceding months. The same may be the case in October and November at Yapi, and it would certainly be accounted for in the case of Kofaba in February. It is worthy of note that at Kapoto the percentage of males in June was also low, viz., 60. This is in distinct contradiction to the percentages found by Newstead in corresponding seasons in Nyasaland. It is worthy of note, however, in connection with Newstead's figures, that the two last numbers given by him (see page 200) are only for a period of over two weeks. Now, although there were very heavy rains during the latter fortnight, it would not materially affect the number of $G$. morsitans in so short a time. Had he taken the whole month's collection together, the percentage would have been approximately the same as in the corresponding two months. This is a clear case, I think, of false deduction from oversubdividing.

In May, however, when I visited the two Bush Camps at Larabanga the percentage of males was even higher than at Larabanga in July and August. This is anomalous, and I will venture no solution, but would only note that these districts were greatly overrun by game. It may be that the food supply was very plentiful and that the females were well fed and therefore more retiring, whereas the greater number of males caught would be accounted for by their being on the look-out for females. This seems to me a more feasible explanation than that given by Bequaert.

\section{Flight Experiments with Glossina.}

In order to ascertain whether Glossina tachinoides liberated at some distance from the river would return to it, I performed a series of experiments by marking a number of specimens by means of cutting off the two terminal tarsi of the various legs. Altogether in these experiments about 3,000 specimens were used. On the road from Yapi to Tamale there are two small streams, about two miles from Yapi, which are dry in the dry season but contain a considerable amount of water in the wet season. Notwithstanding this latter fact, very few $G$. tachinoides are to be found on the banks. They seem to prefer the larger river.

In the first experiment in the dry season I liberated 150 specimens at each of the following distances, 1 mile, $1 \frac{1}{2}$ miles, 2 miles, 3 miles, 4 miles and 5 miles along the main Yapi-Tamale Road. Of these, 59 per cent. liberated at 1 mile were again recaptured, 15 per cent. liberated at $1 \frac{1}{2}$ miles were again caught, while of those liberated at 2 miles only 5 per cent. were retaken on the river bank. Of those liberated at 3 miles and 5 miles, none were taken; while only one liberated at 4 miles was recaptured. None were taken further away from the river than where they were liberated.

When this experiment was again repeated in the wet season, 47 per cent. of those liberated at 1 mile were retaken, 25 per cent. of those liberated at $1 \frac{1}{2}$ miles, and 10 per cent. of those liberated at 2 miles. On the other hand, an examination of the banks of the stream at the different seasons showed a marked disparity. 
During the dry season, when there was no water in the stream, only 3 per cent. of those liberated at 2 miles, 8 per cent. of those liberated at 3 miles, and 6 per cent. of those liberated at 4 miles were again caught, and that at no great distance from the road. None of those liberated at 5 miles were again seen.

In the wet season, however, when water was abundant in the stream, 10 per cent. of those liberated at 2 miles, 13 per cent. of those liberated at 3 miles, 9 per cent. of those liberated at 4 miles, and 6 per cent. of those liberated at 5 miles, were again captured.

Before being liberated, these tsetse were all fed as far as possible, and the cages containing them were taken out at night and left open. It was found that by 2 a.m. all the tsetse had escaped. Of course it must be remembered that there is considerable traffic on this road, and many of these tsetse may have followed the natives for some distance.

However, from these experiments the following deductions may be drawn :-

(1) The greatest distance covered by a single tsetse was four miles.

(2) Apart from this none returned over two miles.

(3) All seemed to return to the water, as none were caught at a greater distance from the river than where they were liberated.

(4) If there was any intermediate water between where the tsetse were liberated and the large river, the tsetse discovered this and were making their way down stream to the large river.

(5) Where there was shade on the bank of a stream but no water, the tsetse congregated there, but did not attempt to proceed towards the large river.

(6) A thorough examination of the open bush on each side of the road revealed not a single tsetse at a greater distance than 200 yards.

(7) There was practically no discrepancy in the proportion of the sexes recaptured ; if anything, there was an excess of males, but the numbers were too small to be of value.

It must be remembered that these numbers may not-in fact, cannot-actually represent the number of tsetse which really returned. The percentages must therefore be taken not as absolute, but as proportionate.

I then tried a similar experiment in the open bush, but found that this was practically impossible owing to the various directions in which the tsetse might return to the sinuous river, and the impracticability of patrolling the whole area.

On another occasion I liberated 1,000 tsetse at distances varying from one to ten miles, along the bank of the river. It was found impossible to collate the returns, but the greatest distance covered by an individual tsetse was seven miles, while numerous flights of 2-4 miles were observed. It is more than probable, however, that these followed the numerous canoes which constantly ply on the river. I have already shown in my various reports the great attraction moving objects have for tsetse.

Of a large number of tsetse liberated at Yapi in September and October 1916, some were taken as late as December 1916, while one was captured 15 miles down the river in January 1916. This is evidently a clear case of a tsetse following a canoe. While tsetse liberated on one bank have been captured on the other, I have not been able to ascertain the total distance covered in one distinct flight. 
In all, ten experiments were tried to test how far tsetse will follow a herd of gamefive original and five repeats. Fifty tsetse (G. submorsitans) were used in each experiment. A herd of cattle passing along a road was selected and the tsetse were liberated in the centre of the herd. In the first set of experiments, the tsetse were not molested, but it must be remembered that cattle are much easier victims to tsetse than are wild game. In the second set, a number of boys with fly switches were ordered to keep disturbing the flies when seen to alight.

The results of these experiments are as follows :-

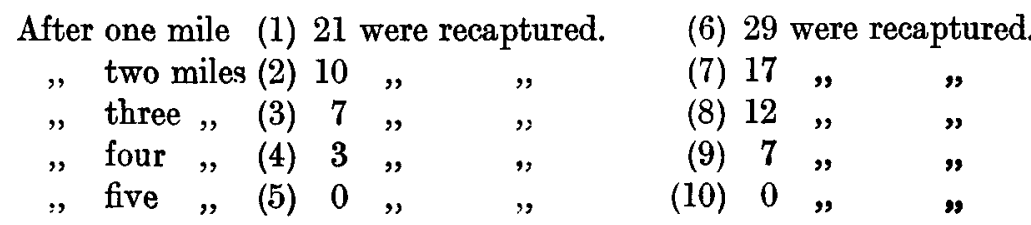

From this series of experiments it will be seen that after five miles have been traversed the tsetse have either all managed to feed, or have given up the attempt and disappeared.

\section{Trapping of Glossina.}

The question of how to diminish the number of tsetse in any definite locality is of paramount importance. It has repeatedly been shown that in the case of villages a clearing of about 400 yards around the outer circumference of the village will practically restrict the tsetse to a region outside this area. This, as Mr. T. E. Fell has pointed out, should be undertaken only when such a clearing can be maintained, otherwise a lower, shorter and more scrubby type of vegetation will arise which is very suitable for the flies. The same must apply to fords of rivers and the main roads in a district. This then should be undertaken only in definite localities where the supply of labour is adequate. In a restricted area, as for example the Island of Principe, such a scheme as systematic trapping has had very beneficial results; but, in wide areas, such as any of the colonies of West Africa, the conditions are totally different. Take, for example, a small portion of the River Volta between Yeji and Yapi. After a week's examination of this part of the river, I am confident in saying that there is not one half mile in this whole area where $G$. tachinoides is not to be found in quantity. There is a constant stream of canoes plying on the river, and it is now certain that tsetse follow these canoes considerable distances. My own experiments have shown a distance of seven miles, and this cannot be regarded as the maximum. Consequently, to attempt to clear this region of tsetse would mean expense out of all proportion to the advantage gained, because the supply on either side would constantly tend to repopulate the whole area.

At the Yapi ferry I posted five men for four months for the purpose of ascertaining if there would be any diminution in the number of tsetse at the end of that time. The following are the results :-

1st-23rd Sept. 1915, 2,876 tsetse caught or 125 per day.

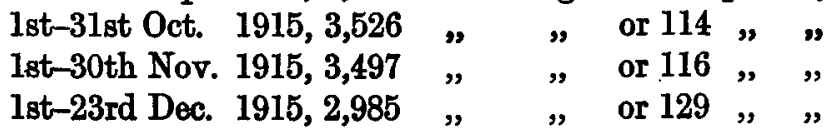


Again, between 22nd February and 23rd March 1916, another test was made with the following result :-3,842 tsetse were caught, or 128 per day. From 21 st November to 23rd December, 4,392 tsetse were caught, or 133 per day.

It must be remembered that collectors were working in this area at several intervening times, so that one is fairly justified in concluding that systematic trapping is out of all question in such an area.

This, it must also be remembered, was accomplished by trained, well paid, fully equipped collectors, and I am of opinion that if the whole population in the area suggested were put on to this work, there would be no appreciable diminution in the number of tsetse. The expense, too, would preclude such an undertaking being attempted.

Systematic trapping with bird-lime I found to be less satisfactory than by means of nets. Four colours of paper were used-light brown, red, black waterproof, and green. These were most satisfactory in the order given.

The following are the average numbers captured daily, five men being used for each colour :-Light brown, 103 ; red,-89; black waterproof, 79 ; green, 45.

In my Gambia report* I have already shown the marked preference of tsetse for black over white in clothing.

I then tried liberating tsetse in an enclosed room and. smearing the bodies of collectors with the following oils and essences :- oil of bergamot, oil of cloves, beechwood oil, oil of lavender, cedarwood oil, beechwood creosote, essence of oranges, and essence of lemon. The tsetse were allowed to alight on and bite the collectors, and only in two cases did these substances seem to act as a deterrent, viz., beechwood creosote and beechwood oil. In the case of oil of cloves and the two essences there seemed to be a marked attraction. The large quantities of these preparations required precluded the experiments from being carried out on a large scale.

Beechwood oil smeared over the hands and face acts as a deterrent to mosquitos so long as the fumes persist.

\section{Natural Enemies of Tsetse.}

The conservation or increase in the numbers of the natural enemies of tsetse is a subject which might well repay consideration. Guinea-fowl and bush-fowl have been mentioned by some writers, especially the late Professor E. A. Minchin. He recommended that these species should be conserved and their range extended, as owing to their scraping habits it was more than probable that they would feed on and destroy tsetse pupae. To test the validity of this hypothesis I examined the stomach contents of 379 of these birds. I found that by far the greatest proportion of the food of both species consisted of guinea-corn and other seeds. From the animal kingdom the following were found, beetles, Syrphid flies, Mantids, ants, bugs, grubs of various sorts, millipedes, grasshoppers, Hymenoptera, molluscs, etc., but in no case did I see any remains of either adult tsetse or pupae.

An examination of the stomach contents of lizards revealed numerous kinds of insects, but never of tsetse. The same is true of the nests of mason wasps. Tsetse are not "fleshy" insects and are therefore unsuitable as a food for growing larvae.

* Bull. Ent. Research, ii, p. 210. 
Bequaert mentions the case of a carnivorous spider as a natural enemy of tsetse, whilst I myself found a predatory Attid spider, Plexippus paykulli, And., capturing G. palpalis on the Government steamer on the Gambia.*

Dragonflies have also been seen devouring tsetse, but by far the most important insect enemies are Asilid flies and wasps of the genus Bembex.

Four species of the former were captured by me with tsetse in their grasp. One of these is an undetermined species of Asilus, while the others are indeterminate both as regards genus and species. Although several species of AsrLIDAE have been seen capturing and devouring tsetse, some take to it more readily than others. I caught a large number with $G$. tachinoides, but very few with $G$. submorsitans. At one place on the Lora River, between Daboya and Larabanga, I fitted up a large mosquito net and enclosed in it numerous tsetse and a few Asilidae. It was noted that most of the tsetse were caught on the wing, only a very few being taken while resting. When an Asilid captures a tsetse, it becomes so engrossed in its prey that it is possible to approach it very closely and note its modus operandi. They seldom fly any great distance after a capture, but alight on some small adjacent twig. Grasping the twig on both sides with the tarsi of all six legs, the Asilid presses the abdomen of the tsetse with all its femora, and inserts its proboscis into the thorax. Although the abdomen be distended with blood, the Asilid very seldom punctures it, but presses the blood into the thorax, and there abstracts it. On a very few occasions I saw the Asilid transfer the proboscis from the thorax to a point between two segments of the abdomen, and suck the blood from there.

The toll of tsetse taken by Asmudar is considerable. They follow cattle and horses long distances, and I have repeatedly seen an Asilid grasp a tsetse about to alight on a horse's neck. Sometimes they will hold a fly for over a quarter of an hour, occasionally shifting the position of the proboscis five or six times. I have also seen them relax their hold of the twig when disturbed, fly away with the tsetse and return to almost the identical spot again. Of 24 tsetse put into a mosquito net with six AsIrIDak, all were dead within 24 hours, and all showed signs of having been punctured.

Bembex is the most voracious enemy of $G$. submorsitans. These insects seem to abound more in the open country than in the shady regions inhabited by $G$. tachinoides. Roubaud states that a species of Bembex attacked and captured $G$. longipalpis, but was not seen in the palpalis area. On one occasion at Larabanga my pony was surrounded by $G$. submorsitans and also small Tabanids. $\dagger$ Numerous Bembex were hovering about and not a few tsetse were captured, although in no case did I see the Bembex attempt to take the Tabanids. The Bembex does not alight, but darts quickly down and either captures the tsetse on the wing or immediately it has alighted. I tried an experiment with tsetse and Bembex in a mosquito net in all respects similar to that with tsetse and AsILIDAE, with the same results.

Thus the AsILIDaE are the chief insect enemies of $G$. tachinoides and Bembex of $G$. submorsitans. Whether or not it would be feasible to breed and disperse these insects it would be highly injudicious to state categorically.

* Bull. Ent. Research, ii, p. 210.

$\uparrow$ See section $(m)$. 


\section{Breeding Places and Habits of Glossina.}

The two species of Glossina with which I was intimately associated during the past tour were $G$. tachinoides and $G$. submorsitans, so that the following remarks apply entirely to them. Zupitza and Yorke \& Blacklock have given some details of the breeding places of $G$. palpalis, but so far I do not think that any work has been done on the two above-mentioned species in West Africa.

On my arrival in the Northern Territories in September $1915 \mathrm{I}$ established my camp at Yapi, and studied $G$. tachinoides almost exclusively. Exhaustive searches along the river bank during that time revealed only a few empty pupal cases, but no live pupae. Despite this fact, females kept in my laboratory produced pupae which matured and developed in due course. The humidity was diminishing and the temperature increasing during this period, and it was found that as this took place the pupal period diminished. The longest time taken by a pupa to hatch was 49 days, and some pupae deposited 25 days after these developed before them. The shortest time taken by a pupa to develop was 22 days. From the pupae deposited in September only 41 per cent. came to maturity, while of those deposited in November 87 per cent. produced adults. Males and females appeared in practically equal. numbers, but the males died off much more quickly than the females. The mortality amongst the males was 35 per cent., amongst the females only 17 per cent. These numbers refer solely to those which died before taking a meal. In January I made an examination of the river between Yapi and Yeji, and again I searched assiduously for pupae at various places, with the same result. I returned to Yapi on 22nd February, and remained there till the 23rd March. During this period I obtained 447 pupae of $G$. tachinoides. Of these 392 produced adults (189 males and 203 females) and none were parasitised.

The breeding places of $G$. tachinoides seem to agree fairly closely with those of G. palpalis. Zupitza, at Duala in the Cameroons, found pupae in the angles of leafsheaths of palms. Yorke and Blacklock never found them there in Sierra Leone, but they found them on the ground around the bases of palms. No palms exist at Yapi, but between Kofaba and Yapi Borassus palms are fairly abundant in some places. A careful search in both positions at these places failed to reveal pupae of G. tachinoides.

The most common situation for the pupae of $G$. tachinoides is in the decaying humus beneath overhanging trees, in places which are quite sheltered from heavy rains and which would be moistened only occasionally by water dripping down. The sun seldom or never penetrates to such positions, and the ground is never really dry. Although this species is very abundant amongst tall grass, I have never found breeding places in such localities, nor have I found them in places which are liable to be flooded at any period of the year. On these occasions I found pupae in hollows of decayed trees, and a more common position is in a collection of decaying leaves in the axils of branches, or in a similar collection at the fracture of a branch which had become partly detached.

On my return to Yapi on 31st May another search was made, and between this date. and the 11th June, 217 pupae were obtained. From these 87 females and 93 males. emerged. 
Between 20th September and 14th October, only 23 pupae were obtained, and between 21st November and 23rd December only 17 pupae were found, although the same and similar places were examined.

This would tend to show that the principal breeding season of $G$. tachinoides is just after the dry season when the rains commence, and that at the end of the rainy season breeding practically ceases.

The breeding places of $G$. submorsitans are very similar to those of $G$. tachinoides, with the exception that on several occasions I have found pupae on the clusters of small growth on the top of deserted anthills, and twice under the overhanging rocks on a scarp at a bush camp at Larabanga.

Lloyd notes that pupae of G. morsitans were found in burrows of bush-pig and warthog. I have never found them in such situations, nor in the burrows of porcupines, which are fairly numerous in the Northern Territories.

At Larabanga, prior to my finding pupae in their natural position, I felled several large trees and surrounded them with a mass of undergrowth, and was successful in inducing $G$. submorsitans to deposit larvae there. On one occasion I saw a female deposit a larva. She took up her position on the underside of the trunk about an inch from the ground and thence let the larva drop. Within five minutes the larva had penetrated the soil and had disappeared.

Pupae of $G$. submorsitans were found at Yarizori, Murugu, Larabanga, Larabanga Bush Camp, Kabampwi and Guripe, all on the Daboya-Bole Road. None were found at Kofaba, or between Kofaba and Yapi. This may be accounted for by the season of the year, namely, January.

From the pupae found (in all 947) 821 adults emerged. Of these 402 were males and 419 females ; 679 gorged themselves with blood, while 124 died before feeding. The males died off much more quickly than the females. Roubaud mentions that he noted intra-uterine pupation; Kinghorn never saw it; I observed it on four separate occasions.

Iloyd states that on one occasion driver ants entered the bottles containing pupae, and that none were damaged. I tested this with eight different species of ants, all with the same result. After prolonged observation, I agree with Lamborn that the viscid fluid around the larva is a protection against carnivorous enemies. The ants approached them, but backed away quite hurriedly before even touching them.

\section{Parasites of Pupae of Glossina.}

Up to the present time no parasites of the pupae of tsetse have been described from West Africa. Now, as I have already shown, there is little hope of the extermination or even diminution of numbers of Glossina by trapping or other methods of destruction. Our only hope in this direction is the systematic breeding of parasites and their dissemination in fly-infested areas. Of course, such an experiment would have to be continued over a long period before any definite result could be expected.

From September to December 1915, I found a large number of pupae of Glossina tachinoides, but from them not a single parasite was obtained. Subsequent investigation showed that a small proportion of them were parasitised by Chalcis amenocles, Walk. This was the only parasite obtained from the pupae of $G$. tachinoides. 
At the Larabanga Bush Camps and at Larabanga itself, between the 15th and 21st August, enormous numbers of pupae and empty pupal cases of $G$. submorsitans were found and from them the following parasites were bred out. These are given in their order of frequency:-Chalcis amenocles, Walk.; Dirhinus inflez̧us, a new species which is being described by Mr. J. Waterston; a Braconid which is being described by Mr. R. E. Turner as Coelalysia glossinophaga; a species of Odontomyia, not yet identified*; and a small Chalcid, which Mr. Waterston has not at present worked out.

In order to ascertain whether these species attacked only Glossina pupae, I placed the newly emerged parasites in bottles with larvae and pupae of several Diptera and also newly deposited larvae of Glossina. The result was rather astonishing, as very few of the Glossina pupae were attacked, whereas nearly every pupa of two species of Sarcophaga was parasitised. By this means I bred out several hundreds of Chalcis amenocles, and also large numbers of the other species. It is worthy of note that of a large number of pupae of Sarcophaga bred out, hardly a single specimen was parasitised in nature. This is not so surprising as might at first sight appear, as the localities in which these pupae are found are in the rubbish heaps and latrines around villages where tsetse are not common.

As species of Sarcophaga are everywhere abundant around villages, and as they breed prolifically, it would be possible in a very short time to obtain very large numbers of these parasites for dissemination.

\section{Fauna of the Northern Territories.}

The relationship between the parasites of game and domestic animals, as well as man, is a subject which has been attracting considerable attention in recent years. Although in West Africa much work has been done in this direction, practically nothing has been accomplished on the West Coast. Consequently, when the grass was burnt down and shooting became practicable, I spent a considerable time in the game area to find out what kinds of game harboured parasites, and what were the species of these parasites. By visiting the game area I was also able to compare the association between tsetse and game. A systematic examination of the blood of horses and cattle was also made for comparison.

The vertebrate fauna of the Northern Territories examined by me included :5 hyaenas (Hyaena crocuta), civet, Paradoxa sp., porcupine, elephant, 1 hippopotamus, buffalo (Syncerus nanus), 4 haartebeste (Bubalis major), 4 roan antelope (Hippotragus equinus), 4 waterbuck, 3 kob (Kobus kob), 1 reed buck (Redunca redunca), 1 bushbuck or harnessed antelope (Tragelaphus scriptus), 2 grey duiker (Cephalophus scriptus), 5 red-flanked duiker (Cephalophus rufilatus), 5 oribi (Ourebia nigricaudata), 1 red-fronted gazelle (Gazella ruffirons), 6 warthog (Phacochaerus aethiopicus), dogfaced baboon (Papio sphinx), red monkey (Cercopithecus patas), brown rat, several

[* Only a single specimen of this Stratiomyi:d fly was sent home by Dr. Simpson, and without any details as to how it was bred. Of the few species of Odontomyia whose life-history is known the larvae live in mud or damp earth or among decayng leaves and therefore the statement that Dr. Simpson's species is a parasite of Glossina would appear to need verification.-ED.] 
species of lizards, crocodile (Crocodilus niloticus and cataphractus), yellow-spotted monitor lizard (Varanus niloticus), puff adder (Bitis arictans), and black cobra (Naia nigricollis).

In the case of the baboon, monkey, civet, porcupine and Paradoxa, negative results were obtained by blood examination. When no parasites were found, guineapigs were injected, but the results were again negative. Consequently, we are fairly safe in asserting that no parasites were present.

In addition to those given in the foregoing list, I also examined two reed-buck, one roan antelope, one bush-buck, and one grey duiker, in July 1914.

It must be here pointed out that Glossina tachinoides calls for consideration as well as G. palpalis and G. submorsitans, as according to Bouet, Roubaud and Gallagher, the former species carries Trypanosoma brucei in its natural state in West Africa. Dr. Moiser also states that at Mulgue, near Maifoni, the natives assert that tsetse kill horses and cattle in that district, and this species is $G$. tachinoides. There can be little doubt that this is so, as it is the most common species on the upper reaches of the River Volta, and practically the only species at Yapi for the greater part of the year. I lost two ponies with trypanosomiasis at Yapi within a few months.

The following are the parasites identified in the blood of the animals shot. Of the three warthog shot at Kofaba on 6th February 1916, two contained a scanty infection of what was apparently Trypanosoma pecorum. Trypanosomes have already been found in the blood of warthog (Bevan). Several writers have noted the close association between tsetse and warthog, although in all fairness I must say that this fact has never been evident to me.

The reed-buck shot at Daboya on 10th April 1914 contained an undoubted infection of $T$. vivax. This fact is extremely important, as the animal was shot not 400 yards from the road and enormous numbers of cattle pass this road daily during the time when the river is low, on their way to Kintampo and Coomassie.

Of the reed-buck shot at the same place on the following day, Dr. J. W. S. Macfie, to whom I submitted the slide says :-

"The reed-buck had a few trypanosomes, some undoubtedly with a free flagellum. I only found a few parasites and it was not easy to make much of them, but I don't think they were $T$. vivax. I think they were of the polymorphic group which includes T. gambiense, $T$. pecaudi, etc. I did not of course find any posterior nuclear forms. All it is possible to say is that the trypanosomes appeared to belong to the polymorphic group (sometimes incorrectly called the $T$. brucei group), and that it is impossible to exclude the chance that they may have been $T$. gambiense."

The blood of both of the oribi shot at Kabampwi on 2nd May 1916 showed a few piroplasms. They were exactly like Theileria mutans, very common in cattle in the Northern Territories. They were either Theileria (Piroplasma) mutans itself, or a closely allied species. Todd and Wolbach have noted a similar parasite in the roan antelope, which they called T. hippotragi, but I do not think one has previously been found in the oribi.

The blood of the haartebeeste shot at Gwa on 20 th June 1916, and that of the redflanked duiker shot at the bush camp at Larabanga on 10th July 1916, both contained a Babesia resembling Theileria parva. 
It is interesting to note that out of the small number of animals examined no fewer than seven contained blood parasites, and that these animals belonged to five different species.

$T$. pecorum is common in cattle and has also been found in horses, while one of my ponies died with an infection of $T$. vivax. It is rather strange that no specimen of $T$. congolense was found in the blood of game, as a large number of cattle and horses examined by me were infected with this species, and I myself lost three ponies with this infection.

Although the blood of a number of hyaenas was examined, it is particularly striking that no Leucocytozoon was found.

\section{Human Trypanosomiasis.}

During my stay in the Northern Territories only two cases of trypanosomiasis in natives came to my notice. One of these was a cook in the employ of Dr. Burgess at Salaga, and the trypanosome was undoubtedly $T$. gambiense. On Dr. Burgess' departure from the Colony I lost sight of the native, so cannot definitely state his progress.

The other was a constable in the Northern Territories' Constabulary in Tamale. He visted Dr. Graham, Provincial M.O. Tamale, with a temperature. Dr. Graham examined his blood and found a trypanosome. He gave him 5 grs. of atoxyl, and from that day onward never succeeded in finding another trypanosome. He wrote. to me about the case, and I suggested that it might be a cattle trypanosome, nonpathogenic to man. A slide of the blood was sent to Dr. Macfie at the laboratory, Accra, who identified it as $T$. vivax.

\section{Blood-sucking Arthropods other than Glossina.}

In order to demonstrate the distribution of these arthropods, the most satisfactory method is to take certain definite areas and show the species found in each locality. This list must be taken as supplementary to those given in my original Report on the Gold Coast.*

Tamale (the headquarters of the Northern Territories): Anopheles costalis, Lw.; $A$. funestus, Giles, A. mauritianus, Grp., A. rufipes, Gough, Stegomyia fasciata, F., S. africana, Theo., S. luteocephala, Newst., Culiciomyia nebulosa, Theo., Mucidus scatophagoides, Theo., Tabanus biguttatus croceus, Surc.

Between Tamale and Yapi: Tabanus biguttatus croceus, Surc., T. taeniola, P. de B., T. sticticollis, Surc., Cordylobia praegrandis, Aust.

Yapi or Tamale Port: Anopheles costalis, Lw., A. funestus, Giles, Stegomyia fasciata, F., S. africana, Theo., S. luteocephala, Newst., Mansonioides uniformis, Theo., M. africanus, Theo., Culex duttoni, Theo., Culicoides sp., Simulium damnosum, Theo., Chrysops distinctipennis, Aust., Tabanus biguttatus croceus, Surc., T. taeniola, P. de B., T. sticticollis, Surc., T. gratus, Lw., T. africanus, Gray, T. subangustus, Ric., T. ditaeniatus, Mcq., T. albipalpus, Walk., T. simpsoni, Aust. 
Between Yapi and Yeji on the River Volta : Tabanus biguttatus croceus, Surc., T. taeniola, P. de B., T. simpsoni, Aust.

Between Yeji and Yapi (overland) :

Yeji : Uranotaenia connali, Edw.

Makongo: Culex quasigelidus, Theo., Ochlerotatus nigeriensis, Theo., Tabrnus sticticollis, Surc., T. gratus, Lw.

Salaga: Auchmeromyia luteola, $\mathbf{F}$.

Kofaba : T. taeniola, P. de B., T. sticticollis, Șurc.

Tomaklaw: T. biguttatus croceus, Surc., T. sticticollis, Surc., T. gratus, Lw.

Between Daboya and Bole :

Larabanga: Tabanus fasciatus, F., T. subangustus, Ric., T. taeniola, P. de B., T. thoracinus, P. de B., Haematopota beringeri, Aust., H. gracilis, Aust., H. bullatifrons, Aust., Hippocentrum versicolor, Aust.

Guripe: Haematopota sp. near tenuis.

Dimawu : Hippocentrum versicolor, Aust.

Murugu : Hippocentrum versicolor, Aust., Haematopota gracilis, Aust., Haematopota sp. near corsoni, Carter.

Kunkwa : Tabanus sticticollis, Surc., T. taeniola, P. de B.

Togoland :

Gnani : Tabanus fasciatus, F., Tabanus sp.

Depoi : Tabanus sticticollis, Surc.

Bimbilla : Tabanus sticticollis, Surc.

Tali : Tabanus biguttatus croceus, Surc., T. sticticollis, Surc.

Chamba : Tabanus sticticollis, Surc.

The following are the five species of ticks and one species of louse which were obtained, with the names of the hosts on which they occurred.

Hyalomma aegyptium, L.
Amblyomma variegatum, F.
Rhipicephalus sanguineus, Latr. $\quad\left\{\begin{array}{c}\text { off roan antelope, } \\ \text { Larabanga, } \\ 23 . \text { vii.14. }\end{array}\right.$

Rhipicephalus sanguineus var. sulcatus, Neum., off bush cat, Yapi, 26.vi.14.

Boophilus australis, Fuller, off roan antelope, Daboya, 23.vi.16.

Hyalomma aegyptium, L. $\left\{\begin{array}{lll}\text { off warthog, } & \text { Daboya, } & 13 . v i .16 . \\ \text { off roan antelope, } & \# & 21 . v i .16 . \\ \text { off roan antelope, } & \# & 23 . v i .16 .\end{array}\right.$

Rhipicephalus falcatus, Neum., off warthog, Daboya, 13.vi.16.

Rnipicephalus sanguineus, Latr. $\left\{\begin{array}{l}\text { off roan, Daboya, 23.vi.16. } \\ \text { off duiker, Gumpe, viii.16. }\end{array}\right.$

Haematopinus eurysternus, N., found on the eyelids of a cow at Yapi.

One of the most outstanding features with regard to the TABANIDAE is the large number of males which were captured at the height of the dry season and until a month before the rains. For example, in the case of Tabanus sticticollis, in December 
1915, 37 कt were taken between Sankwalla and Tamale; 30 $\delta$ and 3 o were captured at Tomaklaw in February 1916; $38 \hat{\sigma}$ at Kofaba; $33 \hat{\sigma}$ between Kofaba and Charma ; 21 t at Makongo and 5 ot Yapi in the same month.

At Kofaba $187 \delta^{t}$ and not a single female of $T$. taeniola were caught by two collectors in one morning around a small water-hole.

In January 1917, 73 of of $T$. sticticollis were captured at Depoi in Togoland, 18 ơ at Bimbilla, 23 ơ at Tali, 10 ơ at Chamba, and 9 ot at Kunkwa.

During the other months hardly a male is to be seen when females are very abundant. 